\title{
A Financial Market Model and Its Application
}

\author{
Zheng Xing Chen
}

\begin{abstract}
A financial market model is developed according to the pricing mechanism in this paper. By simulating the influence among bargainer and price of financial asset, the model can be trained to fitting pricing process in real financial market such as stock market. A proof-test suggested that the model will be available when used in price forecast in short term. Result of forecast shows that the model is effective.
\end{abstract}

Index Terms-Financial market model, simulate, fitting, forecast.

\section{INTRODUCTION}

Usually, in financial market the bargainer composed of investors with different risk appetite. Meanwhile, bargainers affected by each other [1]; for example, some bargainers join the Herd behavior. Bargainer will influence asset price in financial market by collective trading. The new price will also influence the new decision of trading. So the bargainer and the price of asset in financial market are influenced by each other continually.

To analysis the mechanism of pricing process in financial market, researches concentrated in modeling and simulating pricing process had been reported since 1990's. Some of these researches tried to develop a model which has the characteristics of financial market behavior [2], [3], especially the model based on multi agent structure [4], [5] [6], [7]. Other researches were reported to analyze characteristics of price process mechanism [8]-[10].

Those reports had done effective effort to model the pricing mechanism of financial market. But there is a key problem left in this field-How to simulate the pricing process of real market according the mechanism that price of assets influenced by each other?

The purpose of this study is to develop a financial market model by simulating the mechanism which bargainer and price of asset influence each other. With the application of computer, the model should be trained by historic data to fitting the real pricing process in financial market.

\section{The FINANCIAL MARKET MOdEL (FMM)}

\section{A. Hypothesis of the Model}

The hypothesis of the model is listed as follows:

- Bargainer with the same appetite to risk will have the same strategy when trading.

- The decision of trading is due to the changing of assets price including other assets and index.

- The Prospect theory of Kahneman and Tversky is available in the model.

Manuscript received March 14, 2013; revised May 30, 2013.

Zheng Xingchen is with the Financial Research Institute of DRC, Beijing, China (e-mail: zhengxingchen@drc.gov.cn)
According to the Prospect theory of Kahneman and Tversky [11], the relationship between the subjective value and real surplus can be described by $S$ curve. Because the behavior of bargainer is decided by his subjective value in bargaining, here we assume that there is a relationship which can be described as $S$ curve between the influence to bargainer and real surplus. It is showed as Fig.1.

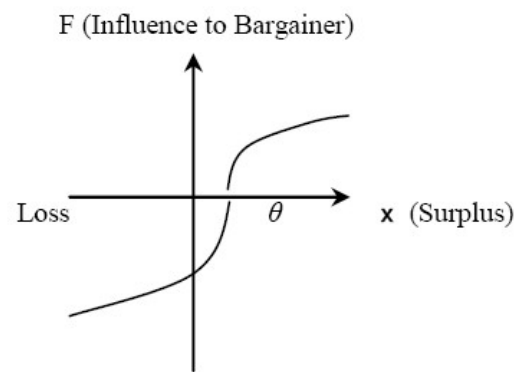

Fig. 1. Relationship between influences to surplus

The parameter $\theta$ indicates the risk averseness of bargainer. The higher $\theta$ means the higher degree of risk averseness, meanwhile, the lower degree of risk appetite.

Because the sensitivity of every bargainer to losing is higher than which to earning, so here the slope of curve above axis $X$ is less than which under axis $X$ in Fig. 1. It can also be described by function (1).

$$
f(x)=\left\{\begin{array}{c}
a \cdot b \cdot \tan \operatorname{sig}(x-\theta), x\rangle \theta, 0<a<1,0<b<1 \\
0, \quad x=\theta \\
b \cdot \tan \operatorname{sig}(x-\theta), x<\theta, 0<b<1
\end{array}\right.
$$

In Chinese stock market, the price changing daily is limited to $10 \%$. The constant $b$ should be $10 \%$. Because $-1<$ $\tan \operatorname{sig}(x)<1$, so the value of $f(x)$ is inside the zone $(-0.1,0.1)$ :

When this function is applied to the financial market model, we can try to simulate the process which bargainer and price influencing each other as Fig. 2.

\section{B. Structure of the Financial Market Model}

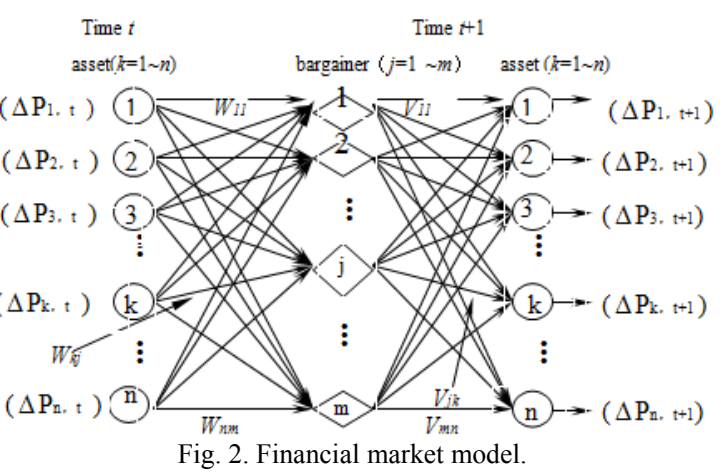

\section{Mechanism of Pricing Process}

In this model, there are $\mathrm{n}$ assets and $\mathrm{m}$ kinds of bargainer. 
Bargainer is partitioned into $\mathrm{m}$ kinds due to the degree of appetite to risk. The degree of bargainer $j$ appetite to risk can be expressed as $\theta_{j}$.

In time $t$, the price of asset $k$ is $P_{k, t}, k=1 \sim n$, and its price fluctuating rate can be expressed by function (2).

$$
\Delta P_{k, t}=\left(P_{k, t}-P_{k, t-1}\right) / P_{k, t-1}
$$

The weight of influence from price fluctuating rate $\Delta P_{k, t}$ to bargainer $j$ is $w_{k j}$, the whole influence come from the price fluctuating rate of $n$ asset of bargainer $j$ is $\sum_{k=1}^{n} w_{k j} \Delta p_{k, t}$.Deducting from $\theta_{j}$, the real influence to the decision of bargainer $j$ is $\sum_{k=1}^{n} w_{k j} \Delta p_{k, t}-\theta_{j}$.

If $\sum_{k=1}^{n} w_{k j} \Delta p_{k, t}-\theta_{j} \neq 0$, bargainer will changing his portfolio of assets. The influence of this changing to whole market will be $f\left(\sum_{k=1}^{n} w_{k j} \Delta p_{k, t}-\theta_{j}\right)$. The function $f(x)$ means the transformation from this influence to the changing of market. The weight of influence from bargainer $j$ to asset $k$ is $v_{j k}$, so the influence from the portfolio changing of bargainer $j$ to the price fluctuating rate of asset $k$ is $v_{j k} f\left(\sum_{k=1}^{n} w_{k j} \Delta p_{k, t}-\theta_{j}\right)$. All the influence from portfolio changing of $m$ kind of bargainer to the price fluctuating rate of asset $k$ is $\sum_{j=1}^{m} v_{j k} f\left(\sum_{k=1}^{n} w_{k j} \Delta p_{k, t}-\theta_{j}\right)$, so $\Delta P_{k, t+1}$ can be expressed by function(3).

$$
\Delta P_{k, t+1}=\sum_{j=1}^{m} v_{j k} f\left(\sum_{k=1}^{n} w_{k j} \Delta p_{k, t}-\theta_{j}\right)
$$

The price of asset $k$ in time $t+1$ can be expressed by function (4).

$$
P_{k, t+1}=P_{k, t}\left(1+\Delta P_{k, t+1}\right)
$$

In this model, the function $f(x)$ is the key factor in describing the process of price fluctuating of asset $k$ deduced form $\Delta P_{k, t}$ to $\Delta P_{k, t+1}$.

\section{Mechanism of Simulation in Real Market}

By the time of the model being trained, parameter $v_{j k}$, $w_{i j}$ and $\theta_{j}$ can be adjusted according to the function (5).

$$
E_{t+1}=\frac{1}{2} \sum_{k=1}^{n}\left(\Delta P_{k, t+1}-\Delta O_{k, t+1}\right)^{2}, k=1 \sim n
$$

Here $\Delta P_{k, t+1}$ is the output of model, and $\Delta O_{k, t+1}$ is the real value of price fluctuating rate. By solving the derivative of $E_{t+1}$, we can get the value of parameter $v_{j k, t+1} w_{i j, t+1}$ and $\theta_{j, t+1}$. When time series of historic data of assets price are inputted into the model, the parameter $v_{j k} w_{i j}$ and $\theta_{j}$ will be adjusted continually.

Here $v_{j k}$ is the weight of influence from bargainer to price of asset. $E_{t+1}$ is the function of $\Delta P_{i, t+1}$, in which $i=1 \sim n$, detail can be expressed by function (6).

$$
\frac{\partial E_{t+1}}{\partial v_{j k}}=\sum_{i=1}^{n} \frac{\partial E_{t+1}}{\partial \Delta P_{i, t+1}} \frac{\partial \Delta P_{i, t+1}}{\partial v_{j k}}
$$

Only $\Delta P_{k, t+1}$ is related with $v_{j k}$, function (6) can be simplified as function (7).

$$
\frac{\partial E_{t+1}}{\partial v_{j k}}=\frac{\partial E_{t+1}}{\partial \Delta P_{k, t+1}} \frac{\partial \Delta P_{k, t+1}}{\partial v_{j k}}
$$

By function (5), we can get function (8).

$$
\frac{\partial E_{t+1}}{\partial \Delta P_{k, t+1}}=\left(\Delta P_{k, t+1}-\Delta O_{k, t+1}\right)
$$

By function (3), we can get function (9).

$$
\frac{\partial \Delta P_{k, t+1}}{\partial v_{j k}}=f\left(\sum_{i=1}^{n} w_{i j} \Delta p_{i, t}-\theta_{j}\right)
$$

There for, we can get function (10).

$$
\frac{\partial E_{t+1}}{\partial v_{j k}}=\left(\Delta P_{k, t+1}-\Delta O_{k, t+1}\right) f\left(\sum_{i=1}^{n} w_{i j} \Delta p_{i, t}-\theta_{j}\right)
$$

Here $w_{i j}$ is weight of influence from price to bargainer. We can get function (11).

$$
\frac{\partial E_{t+1}}{\partial w_{i j}}=\sum_{k=1}^{n} \frac{\partial E_{t+1}}{\partial \Delta P_{k, t+1}} \frac{\partial \Delta P_{k, t+1}}{\partial w_{i j}}
$$

By function (3), we can get function(12).

$$
\frac{\partial \Delta P_{k, t+1}}{\partial w_{i j}}=\Delta P_{i, t} \sum_{j=1}^{m} v_{j k} f^{\prime}\left(\sum_{i=1}^{n} w_{i j} \Delta P_{i, t}-\theta_{j}\right)
$$

Then by function (11) and function (12), we can get function (13).

$$
\frac{\partial E_{t+1}}{\partial w_{i j}}=\sum_{k=1}^{n}\left(\Delta P_{k, t+1}-\Delta O_{k, t+1}\right) \Delta P_{i, t} \sum_{j=1}^{m} v_{j k} f^{\prime}\left(\sum_{i=1}^{n} w_{i j} \Delta P_{i, t}-\theta_{j}\right)
$$

Here $\theta_{j}$ is risk appetite of bargainer. So we can get function (14).

$$
\frac{\partial E_{t+1}}{\partial \theta_{j}}=\sum_{k=1}^{n} \frac{\partial E_{t+1}}{\partial P_{k, t+1}} \frac{\partial P_{k, t+1}}{\partial \theta_{j}}
$$


By function (3), we can get function (15).

$$
\frac{\partial P_{k, t+1}}{\partial \theta_{j}}=-\sum_{j=1}^{m} v_{j i} f^{\prime}\left(\sum_{i=1}^{n} w_{i j} P_{i, t}-\theta_{j}\right)
$$
(16).

By function (14) and function (15), we can get function

$$
\frac{\partial E_{t+1}}{\partial \theta_{j}}=-\sum_{k=1}^{n}\left(\Delta P_{k, t+1}-\Delta O_{k, t+1}\right) \sum_{j=1}^{m} v_{j k} f^{\prime}\left(\sum_{i=1}^{n} w_{i j} P_{i, t}-\theta_{j}\right)
$$

Adjustment of $v_{j k}, w_{i j}, \theta_{j}$ :

According to the principle of making error propagated back along negative gradient, step of adjusting parameter $v_{j k}$ can be set as $\eta$, step of adjusting parameter $w_{i j}, \theta_{j}$ can be set as $\eta^{\prime}$, then we can get function (17) and function (18).

$$
\begin{aligned}
\Delta v_{j k} & =\eta \frac{\partial E_{t+1}}{\partial v_{j k}} \\
v_{j k, t+1} & =v_{j k, t}+\Delta v_{j k}
\end{aligned}
$$

Then by function (10), we can get function (19).

$$
v_{j k, t+1}=v_{j i, t}+\eta\left(\Delta P_{k, t+1}-\Delta O_{k, t+1}\right) f\left(\sum_{i=1}^{n} w_{i j} \Delta p_{i, t}-\theta_{j}\right)
$$

By same way, we can get function (20), function (21), and function (22).

$$
\begin{gathered}
\Delta w_{i j}=\eta^{\prime} \frac{\partial E_{t+1}}{\partial w_{i j}} \\
w_{i j, t+1}=w_{i j, t}+\Delta w_{i j} \\
w_{i j, t+1}=w_{i j, t}+\eta^{\prime} \sum_{k=1}^{n}\left(\Delta P_{k, t+1}-\Delta O_{k, t+1}\right) \Delta P_{i, t} \sum_{j=1}^{m} v_{j k} f^{\prime}\left(\sum_{i=1}^{n} w_{i j} \Delta P_{i, t}-\theta_{j}\right)
\end{gathered}
$$

Parameter $\theta_{j}$ can be adjusted as well, and we can get function (23), function (24), and function (25).

$$
\begin{gathered}
\Delta \theta_{j}=\eta^{\prime} \frac{\partial E_{t+1}}{\partial \theta_{j}} \\
\theta_{j, t+1}=\theta_{j, t}+\Delta \theta_{j} \\
\theta_{j, t+1}=\theta_{j, t}-\eta^{\prime} \sum_{k=1}^{n}\left(\Delta P_{k, t+1}-\Delta O_{k, t+1}\right) \sum_{j=1}^{m} v_{j k} f^{\prime}\left(\sum_{i=1}^{n} w_{i j} P_{i, t}-\theta_{j}\right)
\end{gathered}
$$

To proof-test the model, price forecast of stock in Shanghai Stock Exchange Market will be conducted as follows.

\section{A Proof-Test of Stock Price Forecast}

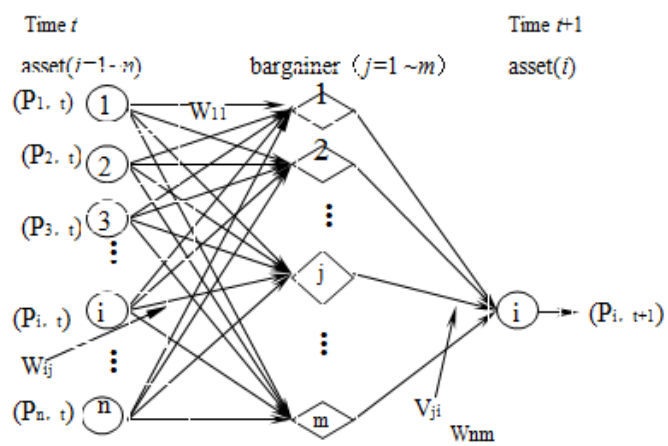

Fig. 3. Financial market model for single target.

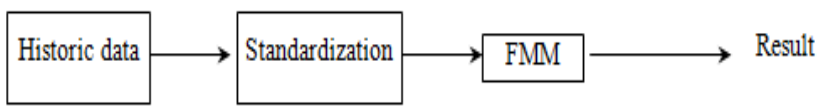

Fig. 4. Process of Forecast through FMM.

TABLE I: ReAl VALUe OF STOCK PRICE

\begin{tabular}{|c|c|c|c|c|c|}
\hline Real value & 600696 & 600693 & 600699 & 600685 & 600691 \\
\hline $1998-01-06$ & 4.92 & 8.38 & 4.75 & 4.3 & 5.84 \\
\hline $1998-01-07$ & 5 & 8.7 & 4.94 & 4.73 & 6.12 \\
\hline $1998-01-08$ & 5.01 & 8.63 & 4.94 & 4.78 & 6.09 \\
\hline
\end{tabular}

TABLE II: STOCK PRICE FORECASTED AND IT'S ERROR

\begin{tabular}{|c|c|c|c|c|c|c|c|c|c|c|}
\hline Output of Model & 600696 & Er. & 600693 & Er. & 600699 & Er. & 600685 & Er. & 600691 & Er. \\
\hline $1998-01-06$ & 4.9139 & $0.1 \%$ & 8.4212 & $0.5 \%$ & 4.6830 & $1.4 \%$ & 4.2845 & $0.4 \%$ & 5.7654 & $1.3 \%$ \\
\hline $1998-01-07$ & 4.9934 & $0.1 \%$ & 8.4483 & $2.9 \%$ & 4.7652 & $3.5 \%$ & 4.3159 & $8.8 \%$ & 5.9481 & $2.8 \%$ \\
\hline $1998-01-08$ & 5.1478 & $2.8 \%$ & 8.7432 & $1.3 \%$ & 4.9548 & $0.3 \%$ & 4.7342 & $1 \%$ & 6.2081 & $1.9 \%$ \\
\hline
\end{tabular}

In the proof-test, the structure of financial market model was transform to adapt for single target simulation and forecasting as Fig. 3 and Fig. 4.

5 stocks were selected in the test. History daily price series data before Dec. 25, 1997 of those stocks were set as input data of the model. By utilizing one of those stock history daily price data as output of the model in simulation, the model was trained to fit the mechanism of price process.

Here the historic daily price fluctuating of stock 600696 . 600693, 600699, 600685, 600691 through Dec. 1, 1995 to Dec. 25, 1997 are applied to this research. Software MATLAB is also applied to data computing. The bargainers are divided into 19 kinds. So it means that, $m=19, n=5$. When the model has being trained, it was applied to forecast the price fluctuating three days later. Real values of target are listed as Table I, results and errors are listed in Table II, with 'Er.' means error.

In this case, there is only 1 datum predicted has its error more than $8.8 \%$, and errors of the rest are all less than $3.5 \%$.

\section{CONCLUSION}

Through the work of test-proof with the FMM in forecasting the daily price fluctuating, we can find that the FMM can be applies to price forecasting in financial market. It means that the model fitting the process of financial assets pricing process well. By this financial market model, we can 
improve decision making for investment in financial market.

\section{REFERENCES}

[1] A. Shleifer, Inefficient Markets: An Introduction to Behavioral Finance, Oxford University Press, pp. 120-150, 2000.

[2] S. Solomon, "Behaviorly realistic simulations of stock market traders with a soul," Computer Physics Communications, pp. 121-122, 161-167, 1999.

[3] A. Ponzi and Y. Aizawa, "Evolutionary financial market models," Physica A, vol. 287, pp. 507-523, 2000

[4] D. F. Holms and S. Trowell, "A Multi-agent modeling environment for market simulation," International Journal of Theoretical and Applied Finance, vol. 3, pp. 487-489, 2000.

[5] M. Raberto, S. Cincotti, S. M. Focardi, and M. Marchesi, Agent Based Simulation of a Financial Market, pp. 319-327, 2001.

[6] D. D. Gatti, C. D. Guilmi, M. Gallegati et al., "Financial fragility, industrial dynamics and business fluctuations in an agent based model," Macroeconomic Dynamics, vol. 11, pp. 62-79, July 2007.

[7] W. X. Zhou and D. Sornette, "Self organizing model of financial markets," The European Physical Journal B, vol. 55, no. 2, pp. 175-181, 2007.

[8] H. J. Chong, Y. K. Ma, Y. B. An, "An analysis of portfolio selection with back ground risk," Journal of Banking \& Finance, vol. 34, pp. 3055-3060, 2010.
[9] I. Foroni and A. Agliari, "Complex price dynamics in a financial market with imitation," Journal of Computational Economics, 2008, vol. 32, no. 1-2, pp. 21-36.

[10] Z. Q. Jiang and W. X. Zou, "Multi fractal in stock index: fact or fiction?" Physica A, vol. 387, no. 14, pp. 3605-3614, 2008.

[11] D. Kahneman and A. Tversky, "Prospect theory: An analysis of decision under risk," Econometrica, vol. 47, pp. 263-292, 1979.

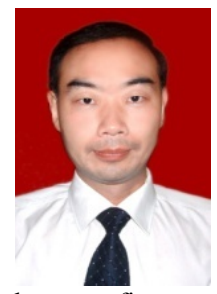

Zheng Xing Chen was born in 1970, China. He was graduated from Zhejiang University of China and was awarded PH.D degree of finance management. He had been worked as division chief of a research institute in local government for several years, and then acted as deputy director general of bureau in local government. He had studied regional economy and finance when worked in local government. By that time, he had studied in promoting cross industry cooperation between finance, shipping and international trade. This project had been endorsed and implemented as APSN in APEC. He is now worked in Financial Research Institute of DRC of China. Main fields of his research are securities market system and rural banking system. He is now engaging with research about rural finance institute reform, development strategy of city commercial bank and its cooperation with industry group, rural financial system survey, and so on. Dr. Zheng also acts as advisor of a national organization, and reviewer of several international conferences as well. 